\title{
Occupational Exposure to Nitrous Oxide and Desflurane during Ear-Nose-Throat-Surgery
}

\author{
Byhahn C*, Wilke HJ , Strouhal U, Kessler P, \\ Lischke $V$ and Westphal $K$ \\ Department of Anesthesiology, Intensive Care Medicine, \\ and Pain Control, JW Goethe-University Hospital Center, \\ Germany \\ *Corresponding author: Byhahn C, Department \\ of Anesthesiology, Intensive Care Medicine, and Pain \\ Control, J.W. Goethe-University Hospital Center, \\ Germany
}

Received: September 14, 2017; Accepted: October 10, 2017; Published: October 17, 2017

\begin{abstract}
Purpose: To determine occupational exposure of the anesthesiologist and surgeon to nitrous oxide and desflurane during general anesthesia for EarNose-Throat (ENT) surgery in children and adults.

Methods: An observational clinical trial was performed in ten children (C) and ten adults (A). Tracheas were intubated, in adults, with cuffed tubes and in children with uncuffed tubes. The operating room was equipped with modern air conditioning and waste anesthetic gas scavengers. Gas samples were obtained during the operative procedure every 90 sec from the breathing zone of subjects. Time-Weighted Averages (TWA) over the time of exposure was calculated for nitrous oxide and desflurane.
\end{abstract}

Results: Nitrous oxide TWAs for anesthesiologists were $0.41 \pm 0.23 \mathrm{ppm}$ (A) and $1.20 \pm 0.32 \mathrm{ppm}(\mathrm{C}, \mathrm{P}<0.0001)$, and $2.24 \pm 1.93 \mathrm{ppm}(\mathrm{A})$ and 5.30 $\pm 0.60 \mathrm{ppm}(\mathrm{C}, \mathrm{P}=0.0001)$ for the surgeon who worked close to the patient's airway and thus had higher exposure $(P<0.05[A], P<0.0001[C])$. With regard to desflurane, the anesthesiologists' TWAs were $0.02 \pm 0.03 \mathrm{ppm}$ for both adults and children. The surgeon was exposed to $0.21 \pm 0.24 \mathrm{ppm}$ desflurane $(A)$ and $0.30 \pm 0.14 \mathrm{ppm}(\mathrm{C}, \mathrm{P}: \mathrm{n}$. s.). Although the surgeon's exposure was greater ( $\mathrm{P}$ $<0.05[\mathrm{~A}], \mathrm{P}<0.0001[\mathrm{C}])$, the threshold limits of $25 \mathrm{ppm}$ for nitrous oxide and $2 \mathrm{ppm}$ for desflurane recommended by the National Institute of Occupational Safety and Health were not exceeded.

Conclusions: Under modern air conditioning, occupational exposure to inhalational anesthetics is low, and inhalational anesthesia is safe from the standpoint of modern workplace laws and health-care regulations.

Keywords: Ear-Nose-Throat Surgery; Anesthesia; Nitrous Oxide; Desflurane

\section{Introduction}

Objective: To determine the level of occupational exposure of anesthesiologist and surgeon to nitrous oxide and desflurane during general anesthesia for ENT intervention in children and adults.

Method: One observational clinical trial was conducted with 10 (E) and 10 (A) adults. Intubation was performed with balloon probes in adults and with balloon less probes in children. The operating room was equipped with a modern air conditioning and anesthetic gas recovery system. The intraoperative gas samples were taken every 90 seconds, in the breathing zone of the subjects. Weighted time averages (MTP) according to exposure time were calculated for nitrous oxide and desflurane.

Results: Nitrous oxide MTPs were $0.41 \pm 0.23 \mathrm{ppm}(\mathrm{A})$ and $1.20 \pm$ $0.32 \mathrm{ppm}(\mathrm{E}, \mathrm{P}<0.0001)$ for the anesthesiologist and 2, $24 \pm 1.93 \mathrm{ppm}$ (A) and $5.30 \pm 0.60 \mathrm{ppm}(\mathrm{E}, \mathrm{P}=0.0001$ for the surgeon who works near the subject's airway and is thus more exposed $(\mathrm{P}<0.05$ As for desflurane, the anesthesiologist's MTP was $0.02 \pm 0.03$ ppm for adults and children and the surgeon's was $0.21 \pm 0.24 \mathrm{ppm}$ desflurane (A) and $0.30 \pm 0.14 \mathrm{ppm}$ (E, P: ns). Even if the surgeon's ex-position was greater $(\mathrm{P}<0.05[\mathrm{~A}] \mathrm{P}<0.0001[\mathrm{E}])$, the limits of $25 \mathrm{ppm}$ for nitrous oxide and $2 \mathrm{ppm}$ for desflurane, as recommended by the National
Institute of Occupational Health and Safety, not exceeded.

Conclusion: Under modern air conditioning conditions, occupational exposure to inhalation anesthetics is low and inhalation anesthesia is safe and compliant with workplace and health care laws.

The discussion of whether chronic exposure to waste anesthetic gases results in adverse effects in health-care workers has taken place as long as inhalational anesthetic agents exist. Numerous studies have been conducted but the results remain controversial and, even if chronic exposure to low levels of these agents does not seem to be responsible for reported health problems, eventual hazards cannot yet be excluded [1-13]. Therefore, it is widely recommended to keep exposure as low as possible. In some countries, strict limits for exposure have been established by governmental agencies. In the United States, the National Institute of Occupational Safety and Health (NIOSH) recommends threshold values of 25 parts per million (ppm) nitrous oxide and $2 \mathrm{ppm}$ of a given volatile anesthetic agent not be exceeded [14].

This study determined the occupational exposure of the anesthesiologist and surgeon to nitrous oxide and desflurane during operative procedures in ear-nose-throat-surgery. 
Table 1: Operating room staffs occupational exposure to nitrous oxide and desflurane during ear-nose-throat surgery.

\begin{tabular}{|c|c|c|c|c|}
\hline & \multicolumn{2}{|c|}{ Adults $(n=10)$} & Children $(n=10)$ & $P$ \\
\hline \multirow[b]{2}{*}{ Inspired desflurane (Vol.\%) } & & & & (adults vs. children) \\
\hline & 6.3 & \pm 0.34 & $6.07 \pm 0.37$ & n.s. \\
\hline Time of exposure (min) & 35 & \pm 4.3 & $36.7 \pm 6.7$ & n.s. \\
\hline \multicolumn{5}{|c|}{ Desflurane exposure (ppm)* } \\
\hline Anesthesiologist & 0.02 & \pm 0.03 & $0.02 \pm 0.03$ & n.s. \\
\hline Surgeon & 0.21 & \pm 0.24 & $0.30 \pm 0.14$ & n.s. \\
\hline \multicolumn{5}{|c|}{$P$ value } \\
\hline (anesthesiologist vs. surgeon) & \multicolumn{2}{|c|}{$P<0.05$} & $P<0.0001$ & \\
\hline \multicolumn{5}{|l|}{ Nitrous oxide exposure (ppm) ${ }^{*}$} \\
\hline Anesthesiologist & 0.41 & \pm 0.23 & $1.20 \pm 0.32$ & $P<0.0001$ \\
\hline Surgeon & 2.24 & \pm 1.93 & $5.30 \pm 0.60$ & $P=0.0001$ \\
\hline \multicolumn{5}{|c|}{$P$ value } \\
\hline (anesthesiologist vs. surgeon) & \multicolumn{2}{|c|}{$P<0.05$} & $P<0.0001$ & \\
\hline
\end{tabular}

Data are given as mean $\pm \mathrm{SD}^{*}$ : Time-Weighted Average (TWA) over the time of exposure.

\section{Materials and Methods}

After approval of the institutional ethics committee and written informed consent of either the patients or their parents, ten adults and ten children who presented for elective ear-nose-throat-surgical procedures were included in the study. Adults underwent pan endoscopies, whereas tonsillectomies were performed in pediatric patients. All surgical procedures were per-formed under general anesthesia.

After premedication with either oral (adult patients) or rectal (pediatric patients) midazolam one hour before induction of anesthesia, all patients underwent intravenous induction, using propofol, fentanyl, and succinylcholine. In adults, the tracheas were intubated using standard cuffed endotracheal tubes, whereas in the pediatric patients uncuffed tubes were employed. Anesthesia was maintained by con-trolled positive-pressure ventilation with nitrous oxide $50 \%$ in oxygen and desflurane at a fresh gas flow of $41 \cdot \mathrm{min}^{-1}$, and supplemented by fentanyl and atracurium as required.

\section{Sampling strategies}

Gas samples were being recorded in a $90 \mathrm{sec}$ sequence throughout the surgical procedure from both anesthesiologist and surgeon simultaneously via tubes that were mounted as close as possible to the subject's mouth. All samples were averaged over the time of exposure to calculate the Time-Weighted Averages (TWA) for nitrous oxide and desflurane. Assessment of waste anesthetic gas concentrations was carried out with a direct reading real-time photoacoustic infrared spectrometer (Brüel \& Kjaer 1302, Naerum, Denmark) that allowed parallel determination of several gases. Concentration curves were generated for nitrous oxide and desflurane. In addition, a number of interfering substances were assessed including glutaraldehyde, 2-propanole, steam, and carbon dioxide. The lower detection threshold of the multigas monitor was $0.015 \mathrm{ppm}$ for desflurane and $0.05 \mathrm{ppm}$ for nitrous oxide.

\section{Environmental settings}

The operating room used during the study had an area of $33.9 \mathrm{~m}^{2}$ and volume of $96.6 \mathrm{~m}^{3}$. The hourly fresh air supply for the operating room was $2,100 \mathrm{~m}^{3}$ with-out recirculation of exhausted air, resulting in 21.7 air exchanges per hour. The air flow entered through the centre of the ceiling and was evacuated in the corners of the room at floor and ceiling level, creating a laminar air flow. Furthermore, the anesthesia machine (Cicero, Draeger, Luebeck, Germany) was connected to a waste gas scavenging system $\left(301 \cdot \mathrm{min}^{-1}\right)$.

\section{Statistics}

Once Gaussian distributions of the data were con-firmed, an unpaired t-test was used to compare the data in terms of means and standard deviations. All statistical calculations were performed with Graph Pad in Stat Version 3.00 (Graph Pad Software, Inc., San Diego, CA, USA). Statistical significance was confirmed with a probability of error less than $5 \%(P<0.05)$.

\section{Results}

Ten children and ten adults who were otherwise healthy underwent general inhalational anesthesia for elective tonsillectomy or pan endoscopy, respectively. During anesthesia, in all patients the lungs were mechanically ventilated with peak inspiratory pressures of $17.2 \pm 2.1$ mbar in children and $18.4 \pm 2.9$ mbar in adults (P: NS). Measurements were made throughout the surgical procedures which lasted on the average $36.7 \pm 6.7 \mathrm{~min}$ for tonsillectomies and $35.0 \pm 4.3$ min for pan endoscopies, respectively.

The average concentrations of the anesthetic gases used were low in the breathing zone of both the anesthesiologist and the surgeon during surgery (Table 1). Nonetheless, during tonsillectomy in children, the anesthesiologist's exposure to nitrous oxide was higher than during pan endoscopic procedures in adults. These results also applied to the surgeon. Furthermore, the surgeon who worked in closer proximity to the patient's air-ways was exposed to higher levels of both desflurane and nitrous oxide than was the anesthesiologist, who stayed at the opposite end of the operating table during surgery.

Although waste anesthetic gas concentrations were measurable, the recommended threshold values given by the NIOSH of $25 \mathrm{ppm}$ for nitrous oxide and $2 \mathrm{ppm}$ for volatile anesthetics as a time-weighted average over the time of exposure were not violated at any time. 


\section{Discussion}

During inhalational anesthesia with nitrous oxide and desflurane, trace concentrations of the agents used were detected in the operating room air, resulting in chronic exposure of the operating room staff. Chronic exposure to trace concentrations of inhalational anesthetics is believed to have adverse effects on the health of exposed personnel and, during the past decade, a few studies suggested a correlation between chronic exposure and reproductive toxicity [15-17]. However, a clear relationship between the level of exposure and the reported health hazards has not been proved. Nonetheless, exposure limits have been recommended by governmental agencies in the United States and other countries.

During our study, the time-weighted averages of the inhalational agents used were below the threshold limits of $25 \mathrm{ppm}$ for nitrous oxide and $2 \mathrm{ppm}$ for desflurane recommended by the NIOSH. The average concentrations of nitrous oxide ranged from $0.41 \pm 0.23$ $\mathrm{ppm}$ to $5.30 \pm 0.60 \mathrm{ppm}$, and average desflurane levels were $0.02 \pm$ 0.03 to $0.30 \pm 0.14 \mathrm{ppm}$. Maximum concentrations were measured in the breathing zone of the surgeon during anesthesia in children and infants. In every instance, the surgeon was exposed to higher levels of the anesthetic agents used than was the anesthesiologist. These results can most likely be attributed to the fact that the surgeon was working close to the patient's airways, whereas the anesthesiologist worked at the opposite end of the operating table at the patient's feet, about $2.5 \mathrm{~m}$ from the patient's mouth. Although both physicians were working in the centre of the operating room, directly under the air conditioning vents and thus within an area of laminar air flow, exposure levels appear to depend on the proximity to the endotracheal tube. In addition, draping placed over the patient might have separated the anesthesiologist from the escaping anesthetic gases.

Furthermore, both the anesthesiologist and the surgeon were exposed too much higher levels of nitrous oxide during general anesthesia in infants and children than in adults, whereas the desflurane concentrations were similarly low or only slightly increased. Because the inspired concentrations of nitrous oxide were identical in children and adults, these results are most likely attributable to the use of uncuffed endotracheal tubes in pediatric patients. In contrast to cuffed tubes, uncuffed tubes do not fit tightly in the trachea, resulting in tracheal air leak, and therefore lead to higher levels of exposure. These results are in agreement with a number of studies that also demonstrated that the use of uncuffed tubes during pediatric anesthesia represents a considerable pollution hazard $[18,19]$, However, it is not clear why these findings applied more clearly to nitrous oxide than to desflurane during our study.

In addition to efficient air conditioning and waste anesthetic gas scavengers which contribute considerably to the reduction and prevention of air pollution [20,21], and which were used during our study, further strategies have been demonstrated to minimize personnel's occupational exposure during intubation anesthesia. Local scavenging devices mounted near the patient's mouth are able to reduce exposure levels [22], but they are noisy and, during EarNose-Throat-Surgery, interfere with the surgical procedure. Other studies have demonstrated that the level of exposure depends on the fresh gas flow during anesthesia [23]. Thus, fresh gas flow reduction should be considered whenever possible, and a high fresh gas flow of
$41 \bullet \mathrm{min}^{-1}$ as during our study should not be used when anesthesia is maintained with inhalational agents.

Another important source of contamination is air leaks in the circuit of the anesthesia machine. The machine should be checked frequently to detect leakage. Finally, leakage from the wall-mounted gas outlet sockets that provide nitrous oxide from the central gas system to the anesthesia machines may result in considerable contamination of the operating room. Baseline contamination in operating rooms have been demonstrated to be as high as 4ppm [24], representing concentrations that were at least comparable to the concentrations from use of nitrous oxide during anesthesia itself in the recent study.

Under modern air conditioning, personnel occupational exposure to nitrous oxide and desflurane was low during our study, and inhalational anesthesia is safe from the standpoint of modern workplace laws and healthcare regulations. Nonetheless, only increased and constant awareness of this problem will keep occupational exposure at this low level.

\section{References}

1. Klatskin G, Kimberg DV. Recurrent hepatitis attributable to halothane sensitization in an anesthetist. N Engl J Med. 1969; 280: 515-522.

2. Cohen EN, Bellville JW, Brown BW Jr. Anesthesia, pregnancy, and miscarriage: a study of operating room nurses and anesthetists. Anesthesiology. 1971; 35: 343-347.

3. Corbett TH, Cornell RG, Lieding K, Endres JL. Incidence of cancer among Michigan nurse-anesthetists. Anesthesiology. 1973; 38: 260-263.

4. Cohen EN, Brown BW, Bruce DL, et al. Occupational disease among operating room personnel: A national study. Anesthesiology. 1974; 41: 321 340 .

5. Corbett TH, Cornell RG, Endres JL, Lieding K. Birth defects among children of nurse-anesthetists. Anesthesiology. 1974; 41: 341-344.

6. Baden JM, Kelly M, Cheung A, Mortelmans K. Lack of mutagens in urines of operating room personnel. Anesthesiology. 1980; 53: 195-198.

7. Cohen EN, Gift HC, Brown BW, et al. Occupational disease in dentistry and chronic exposure to trace anesthetic gases. J Am Dent Assoc. 1980; 101: 21-31.

8. Sweeney B, Bingham RM, Amos RJ, Petty AC, Cole PV. Toxicity of bone marrow in dentists exposed to nitrous oxide. BMJ. 1985; 291: 567-569.

9. Karelová J, Jablonická A, Gavora J, Hano L. Chromosome and sisterchromatid exchange analysis in peripheral lymphocytes, and mutagenicity of urine in anesthesiology personnel. Int Arch Occup Environ Health. 1992; 64: 303-306.

10. Karakaya A, Tuncel N, Yücesoy B, et al. The effects of volatile anesthetic agents on human immune system function via occupational exposure. Immunopharmacol. Immunotoxicol. 1992; 14: 251-259.

11. Malhotra SK, Dhananjaya PR, Singh H, Pershad D. Effect of halothane exposure on motor skills \& memory in anesthetists. Indian J Med Res. 1993; 98: $218-222$.

12. Chang WP, Lee S-R, Tu J, Hseu S. Increased micronucleus formation in nurses with occupational nitrous oxide exposure in operating theaters. Environ Mol Mutagen. 1996; 27: 93-97.

13. Lucchini R, Placidi D, Toffoletto F, Alessio L. Neurotoxicity in operating room personnel working with gaseous and nongaseous anesthesia. Int Arch Occup Environ Health. 1996; 68: 188-192.

14. NIOSH. NIOSH pocket guide to chemical hazards. Washington, DC: United States Government Printing Office. 1994.

15. Guirguis SS, Pelmear PL, Roy ML, Wong L. Health effects associated with 
exposure to anesthetic gases in Ontario hospital personnel. $\mathrm{Br} \mathrm{J}$ Ind Med. 1990; 47: 490-497

16. Rowland AS, Baird DD, Weinberg CR, Shore DL, Shy CM, Wilcox AJ Reduced fertility among women employed as dental assistants exposed to high levels of nitrous oxide. N Engl J Med. 1992; 327: 993-997.

17. Rowland AS, Baird DD, Shore DL, Weinberg CR, Savitz DA, Wilcox AJ Nitrous oxide and spontaneous abortion in female dental assistants. Am J Epidemiol. 1995; 141: 531-538.

18. Hoerauf K, Funk W, Harth M, Hobbhahn J. Occupational exposure to sevoflurane, halothane and nitrous oxide during pediatric anesthesia. Anesthesia. 1997; 52: 215-219.

19. Byhahn C, Westphal K, Wilke H-J, Lischke V. Occupational exposure during mask induction and use of different types of endotracheal tubes. (German) Anaesth Intensivmed. 1998; 39: 627-632.
20. Breum NO, Kann T. Elimination of waste anesthetic gases from operating theatres. Acta Anaesthesiol Scand. 1988; 32: 388-390.

21. Hobbhahn J, Hoerauf K, Wiesner G, Schröegendorfer K, Taeger K. Waste gas exposure during desflurane and isoflurane anesthesia. Acta Anaesthesiol Scand. 1998; 42: 864-867.

22. Sik MJ, Lewis RB, Eveleigh DJ. Assessment of a scavenging device for use in pediatric anesthesia. $\mathrm{Br} \mathrm{J}$ Anaesth. 1990; 64: 117-123.

23. Imberti R, Preseglio I, Imbriani M, Ghittori S, Cimino F, Mapelli A. Low flow anesthesia reduces occupational exposure to inhalation anesthetics. Environmental and biological measurements in operating room personnel. Acta Anaesthesiol Scand. 1995; 39: 586-591.

24. Byhahn C, Westphal CK. Causes of nitrous oxide contamination in operating rooms (Letter). Anesthesiology. 1999; 91: 1960-1961.
Austin J Anesthesia and Analgesia - Volume 5 Issue 2 - 2017

ISSN : 2381-893X | www.austinpublishing group.com

Byhahn et al. (C) All rights are reserved
Citation: Byhahn C, Wilke HJ, Strouhal U, Kessler P, Lischke V and Westphal K. Occupational Exposure to Nitrous Oxide and Desflurane during Ear-Nose-Throat-Surgery. Austin J Anesthesia and Analgesia. 2017; 5(2): 1059. 